\title{
DESENVOLVIMENTO DE FARINHAS MISTAS EXTRUSADAS À BASE DE FARINHA DE MILHO, DERIVADOS DE LEVEDURA E CASEÍNA ${ }^{1}$
}

\author{
Izabela Dutra ALVIM², Valdemiro Carlos SGARBIERI ${ }^{2, *}$, Yoon Kil CHANG ${ }^{3}$
}

\begin{abstract}
RESUMO
O presente trabalho teve como principal objetivo o desenvolvimento de farinhas mistas extrusadas à base de farinha de milho, derivados de levedura (autolisado ou extrato) e caseína como ingredientes. Utilizou-se a extrusão como processo, sem a pretensão de otimizálo, mas buscando as condições que permitissem uma boa operacionalidade do extrusor e produtos extrusados com boas propriedades funcionais, boa aceitação e elevado valor nutritivo. As condições adotadas para o processo foram: alimentação do extrusor, $85 \mathrm{~g} / \mathrm{min}$; velocidade do parafuso, 150rpm; relação de compressão do parafuso, 1:3; umidade inicial da amostra, 25\%; e temperatura de extrusão $170^{\circ} \mathrm{C}$. A melhoria das características nutritivas foi assegurada pela elevação dos teores de proteína e de fibra e diminuição do teor de carboidrato, em relação à farinha sem adição. A extrusão promoveu um adequado grau de expansão radial (GER), aumentou os índices de absorção e de solubilidade em água e diminuiu sensivelmente a viscosidade, em relação à farinha de milho crua.

Palavras-chave: farinha de milho; farinha mista; derivados de levedura; extrusão.
\end{abstract}

\section{SUMMARY}

DEVELOPMENT OF EXTRUDED MIXED FLOURS BASED ON CORN FLOUR, YEAST DERIVATIVES AND CASEIN. The main objective of the present work was the development of extruded mixed flours based on corn flour, yeast derivatives (autolysate or extract), and casein, as ingredients. The extrusion process was used as unit operation with the purpose of achieving good operation condition for the equipment, and extruded products of good functional properties and acceptability and high nutritive properties. The adopted operational conditions for the process were: feeding rate of the extruder; $85 \mathrm{~g} / \mathrm{min}$; screw velocity, 150rpm; screw compression ratio, $1: 3$; sample initial moisture, $25 \%$; and extrusion temperature, $170^{\circ} \mathrm{C}$. Improvement of the nutritional characteristics was assured by the elevation of protein and total fiber content and a decrease in carbohydrate, as related to the corn flour without enrichment. The extrusion promoted an adequate degree of radial expansion (DRE), increased the indexes of water absorption (IWA) and solubility (IWS), and significantly decreased viscosity, as related to the unextruded corn flour.

Keywords: corn flours; mixed flour; yeast derivatives; extrusion.

\section{1 - INTRODUÇÃO}

A farinha de milho é muito utilizada na culinária brasileira em várias formas e o seu sabor é muito bem aceito pelos consumidores. É um produto de baixo custo e amplamente disponível no mercado. É uma rica fonte de carboidrato, contendo ainda ao redor de $10 \%$ de proteína.

Do ponto de vista nutritivo, sua proteína é de baixíssima qualidade, por ser bastante limitante em lisina e em triptofano, que são aminoácidos essenciais na dieta [15]. Por esse motivo e pela escassez de produtos protéicos de baixo custo e alto valor nutritivo, tem havido uma busca permanente de novas fontes de proteína que atendam aos quesitos de baixo custo de produção e alto valor protéico $[11,16]$.

O enriquecimento de produtos convencionais com os derivados de cereais, largamente disponivel e de boa aceitação pela população, com ingredientes de elevado valor nutritivo, é o caminho mais curto e mais econômico para se oferecer à população alimentos nutritivos a um custo competitivo com seus similares no mercado.

A biomassa de levedura, em sua forma integral ou de seus derivados, apresenta elevado valor nutritivo, baixo custo de produção e tem sido largamente utilizada como ingrediente na formulação de um amplo espectro de produtos alimentícios para humanos. [4, 5, 9].

A caseína bovina pode ser obtida em grande quantidade por processos tecnológicos a baixo custo, tanto pela precipitação ácida (caseína isoelétrica) como pela coagulação enzimática [17]. Em virtude do crescente interesse da indústria na produção de proteínas de soro de leite, poderemos ter, em futuro próximo, quantidade muito grande de caseína no mercado.

Devido ao seu elevado valor nutritivo e excelente funcionalidade, aliadas ao baixo custo de produção, a caseína se apresenta como um ingrediente de primeira linha para o enriquecimento e produção de alimentos protéicos para fins específicos. Ela tem sido usada na produção de produtos cárneos, produtos de laticínios, produtos de panificação, chocolates, confeitos, produtos de cobertura, cremes para café e "snacks" [6, 20].

Esta pesquisa constitui parte de um projeto bastante amplo que visa a utilização da biomassa de levedura e de seus derivados como ingrediente na formulação ou enriquecimento de produtos para alimentação humana.

Em particular, este trabalho se propôs a desenvolver farinhas mistas contendo farinha de milho, derivados de levedura e caseína pelo processo de extrusão termoplástica, visando a obtenção de produtos de boa funcionalidade, boa aceitação e elevado valor nutritivo.

\footnotetext{
${ }^{1}$ Recebido para publicação em 07/08/01. Aceito para publicação em 28/11/01.

${ }^{2}$ Instituto de Tecnologia de Alimentos (ITAL), Av. Brasil, 2880, CEP 13073-001, Campinas, SP.

${ }^{3}$ Faculdade de Engenharia de Alimentos, UNICAMP, Departamento de Tecnologia de Alimentos, Cx. Postal 6121, CEP 13083-970, Campinas-SP.

* A quem a correspondência deve ser enviada.
} 


\section{2 - MATERIAL E MÉTODOS}

\section{1 - Materiais}

$\mathrm{Na}$ formulação das farinhas mistas foram utilizadas os seguintes ingredientes: a) farinha de milho comercial (fubá mimoso marca Yoki); b) autolisado (A) da levedura Saccharomyces cerevisiae, obtida como sub-produto da fabricação de álcool etílico; c) extrato de levedura (E), da mesma origem; d) coágulo de caseína desidratado, obtido no processo de coagulação enzimática do leite bovino.

\section{2 - Métodos}

\subsection{1 - Lavagem e desidratação da biomassa de levedura}

A levedura foi coletada na destilaria de álcool em suspensão de aproximadamente $30 \%$ de células e transportada para a planta de operações unitárias do ITAL, em recipientes de $200 \mathrm{~L}$, e armazenada sob refrigeração $\left(5^{\circ} \mathrm{C}\right)$. Em seguida, as células foram coletadas por centrifugação (centrífuga de pratos Alpha-Laval) e submetidas a dois ciclos de lavagem com água (suspensão 1:1 sólido/líquido). A desidratação da biomassa lavada foi feita em secador "spray dryer" (Niro Atomizer, Dinamarca).

\subsection{2 - Obtenção dos derivados de levedura}

A biomassa lavada e desidratada foi inicialmente submetida ao processo de autólise, com base nos procedimentos descritos por KOLLAR, STUDIRK, FARKAS [10] e SGARBIERI et al. [18]. Em síntese, as condições da autólise foram: suspensão de levedura a 10\% (p/v); adição de plasmolisantes, $\mathrm{NaCl} 2 \%(\mathrm{p} / \mathrm{p})$, etanol 7\% (p/p); adição de um pré-autolisado $7 \%(\mathrm{v} / \mathrm{v})$; temperatura $55 \pm$ $2^{\circ} \mathrm{C}$; $\mathrm{pH}$ 5,0-5,5; tempo de autólise $24 \mathrm{~h}$. O pré-autolisado foi produzido a partir de uma suspensão de levedura a $10 \%(\mathrm{p} / \mathrm{v})$ e autolisada nas condições prescritas, exceto pelo tempo de autólise que foi de apenas 6 horas.

A autólise foi conduzida em fermentador com capacidade para 250L (New Brunswick Scientific Co. Inc.; Mod. Nat'l BD 1630), munido de sistema de agitação mecânica e temperatura controlada (Controlador MI 4100) que alterna vapor e água.

Cada batelada de autolisado constava de $172,5 \mathrm{~L}$ (150L da suspensão de levedura mais $22,5 \mathrm{~L}$ de préautolisado).

Terminada a autólise, a temperatura era elevada para $85^{\circ} \mathrm{C}$ e mantida por $15 \mathrm{~min}$, para inativação enzimática. Em seguida, o autolisado era resfriado e submetido à desidratação em "spray dryer" para obtenção do autolisado (A) desidratado.

Lotes de autolisado foram também submetidos à centrifugação em centrífuga Alpha-Laval (5.000rpm, fluxo de $100 \mathrm{~L} / \mathrm{h})$ para obtenção do extrato de levedura (E). Após separação da parte insolúvel, o extrato foi submetido à concentração, sob vácuo $\left(0,8 \mathrm{~atm}, 50\right.$ a $\left.65^{\circ} \mathrm{C}\right)$, até atingir um teor de sólidos de aproximadamente $20 \%$. Antes da secagem em "spray dryer", o extrato foi adicionado de maltodextrina, na base de $25 \%$ (p/p) em relação aos sólidos. A maltodextrina tem a função de auxiliar na secagem e tornar o extrato menos higroscópico.

\subsection{3 - Obtenção do coágulo de caseina desidra- tado}

O coágulo de caseína desidratado foi obtido a partir do leite desnatado e pasteurizado $\left(74^{\circ} \mathrm{C}, 20\right.$ seg.), conforme descrito em BORGES et al. [3]. A coagulação foi feita a $34^{\circ} \mathrm{C}$ por $40-60 \mathrm{~min}$, pela ação das enzimas quimosina/ pepsina contidas no coágulo comercial líquido. Utilizaram-se $300 \mathrm{~mL}$ de coágulo/100L de leite mais 25mL/ 100L de solução de $\mathrm{CaCl}_{2}$ a 50\%. O coágulo foi separado do soro por filtração e lavado exaustivamente com água, para eliminação do máximo possivel de soro e outros contaminantes.

Após lavagem, o coágulo foi moído (moinho coloidal) em presença de solução de $\mathrm{NaOH}$, ajustando-se o $\mathrm{pH}$ entre 7,5-8,5. Em seguida, procedeu-se a desidratação da suspensão coloidal em "spray dryer" (Niro Atomizer), usando temperatura na entrada de $190^{\circ} \mathrm{C}$ e na saída do aparelho, $90^{\circ} \mathrm{C}$.

\subsection{4 - Extrusão da farinha de milho e das fari- nhas mistas}

A extrusão é empregada na produção de cereais matinais e expandidos, produtos texturizados, farinhas e amidos pré-gelatinizados utilizados na formulação de sopas de preparo rápido, molhos semi-processados, produtos de confeitaria, entre outros [8, 14].

Nesta pesquisa, não se buscou a otimização do processo, mas sim a utilização da extrusão como uma operação unitária que permitisse a obtenção de farinhas précozidas e/ou produtos formatados com boas características funcionais e nutritivas, observando sempre as condições de boa operacionalidade do extrusor.

No processo, foram fixadas: velocidade de alimentação do equipamento $(85 \mathrm{~g} / \mathrm{min})$; velocidade de rotação do parafuso (150rpm); relação de compressão do parafuso (1:3); forma e diâmetro da matriz. As variáveis independentes testadas foram: adição de derivados de levedura à farinha de milho (5 e 10\%); umidade inicial na farinha a ser extrusada $(20,25$ e $30 \%)$; temperatura de extrusão $\left(130\right.$ e $\left.170^{\circ} \mathrm{C}\right)$.

Após uma série de experiências preliminares, observando-se a operacionalidade do processo e a qualidade do produto extrusado, foram adotadas como condições satisfatórias: umidade inicial da farinha 25\%; nivel de adição de derivado de levedura e/ou caseína à farinha de milho, $10 \%$ (p/p); temperatura de extrusão, $170^{\circ} \mathrm{C}$.

Utilizou-se nas experiências, um extrusor de laboratório de um único parafuso de marca Brabender mod. 826.801. A monitoração do processo foi feita pela observação do desempenho na extrusão, a saber: variação no torque (constante ou irregular); barulhos estranhos durante a extrusão (ruídos e estalos não característicos); 
fluidez do material ao longo do processo (saída sem interrupções ou entupimento), além das determinações do grau de expansão radial, cor, crocância, índices de absorção e de solubilidade em água.

\subsection{5 - Métodos analiticos}

- Proteína bruta (N x F). Determinada pelo método micro-Kjeldahl, segundo procedimento descrito no AOAC [1]. O fator de conversão utilizado foi o mais apropriado para cada tipo de proteína.

- Teor de umidade. Determinado em estufa a $105^{\circ} \mathrm{C}$ por $24 \mathrm{~h}$, de acordo com o método da A.O.A.C. [1].

- Teor de cinza. Fez-se a carbonização das amostras seguida de incineração a $225^{\circ} \mathrm{C}$ por $24 \mathrm{~h}$, segundo A.O.A.C. [1].

- Lipídios totais. Foi utilizado o método descrito por BLIGH \& DYER [2], tendo como solvente a mistura clorofórmio (10mL), metanol $(20 \mathrm{~mL})$ e água $(8 \mathrm{~mL})$.

- Fibra alimentar total. Foi usado o método enzimático/ gravimétrico que se baseia na gelatinização e hidrólise do amido e hidrólise das proteínas das amostras pela ação das enzimas específicas e precipitação da fibra pelo etanol, PROSCKY et al. [13] e A.O.A.C. [1].

- Carboidrato. Foi estimado pela diferença entre $100 \%$ e a soma das porcentagens dos demais componentes da amostra.

- Viscosidade. O perfil de viscosidade das farinhas foi determinado usando-se o Analisador Rápido de Viscosidade (Rapid Visco Analyser), modelo RVA 3D+ da New Port Scientific Pty. Ltd., Sidney, Austrália, provido do software Termocline.

\section{3 - RESULTADOS E DISCUSSÃO}

\section{1 - Composição centesimal aproximada dos ingre- dientes}

A Tabela 1 apresenta a composição da farinha de milho utilizada e dos ingredientes enriquecedores que foram adicionados na composição das farinhas mistas.

TABELA 1. Composição centesimal aproximada dos ingredientes utilizados na formulação de farinhas mistas extrusadas

\begin{tabular}{lcccc}
\hline \multicolumn{1}{c}{ Componente (\%) } & \multicolumn{4}{c}{ Ingredientes } \\
\cline { 2 - 5 } & $\begin{array}{c}\text { Farinha de } \\
\text { milho }^{\mathrm{a}}\end{array}$ & $\begin{array}{c}\text { Autolisado de } \\
\text { levedura }\end{array}$ & $\begin{array}{c}\text { Extrato de } \\
\text { levedura }^{\mathrm{c}}\end{array}$ & Caseína $^{\mathrm{d}}$ \\
\hline $\begin{array}{l}\text { Proteína bruta } \\
\quad(\mathrm{NxF})^{*}\end{array}$ & 9,5 & 37,1 & 44,8 & 80,6 \\
$\begin{array}{l}\text { Lipídios totais } \\
\text { Fibra alimentar }\end{array}$ & 3,8 & 1,9 & 0,5 & 1,6 \\
Total & 4,1 & 40,6 & 3,9 & - \\
Cinzas & 0,9 & 6,7 & 13,1 & 9,0 \\
Carboidratos & 81,7 & 13,7 & 37,7 & 8,8 \\
(diferença) & & & & \\
\hline
\end{tabular}

${ }^{*} \mathrm{~F}:{ }^{\mathrm{a}}, 6,25 ;{ }^{\text {b }}, 5,8 ;{ }^{\text {c }}, 5,8 ;{ }^{\text {d }}, 6,38$

Observa-se que a farinha de milho apresenta um baixo teor de proteína e um teor bastante elevado de carboidrato, predominantemente amido.
Os derivados de levedura (autolisado e extrato) diferem principalmente em relação aos teores de proteína, de fibra total, de minerais (cinzas) e de carboidrato. $\mathrm{O}$ autolisado, por representar basicamente a levedura integral, isto é, conter na sua composição tanto os componentes solúveis das células como os insolúveis (parede celular) apresenta, em relação ao extrato, teor mais baixo de proteína, concentração bem mais alta de fibra total e teores mais baixos de minerais e de carboidratos que o extrato. Os teores mais elevados de cinza e de carboidrato no extrato são explicados pela adição de $\mathrm{NaCl}$ ( $2 \% \mathrm{p} / \mathrm{p})$ no processo de autólise da biomassa, enquanto que o elevado teor de carboidrato se deve à adição de maltodextrina (25\% p/p dos sólidos), previamente à secagem em "spray". A maltodextrina facilita a secagem e melhora as propriedades físicas do produto acabado, no que diz respeito á granulometria e higroscopicidade.

\section{2 - Formulação das misturas e extrusão da farinha de milho e das farinhas mistas}

WHALEN et al. [21], RHEE, CHO, PRADAHN [14] e MILLER [12] mostraram uma relação inversa entre expansão do material extrusado e teor de umidade inicial. MILLER [12] justifica que em altas umidades, o gel é mais elástico, formando uma matriz de pequenas células uniformes, enquanto que em baixa umidade, o material extrusado tem células grandes e pouco uniformes e o gel formado é pouco elástico. O grau de expansão radial é proporcional à temperatura até um certo valor para depois decrescer em temperaturas mais elevadas [19].

Em condições de menor temperatura $\left(130^{\circ} \mathrm{C}\right)$ e mais alta umidade (30\%), obtiveram-se os menores graus de expansão radial (GER), os produtos apresentaram-se bastante escuros, duros e de aspecto irregular. Na faixa de umidade intermediária (25\%), o GER e a operacionalidade do extrusor foram satisfatórias, porém, os produtos processados nessa umidade e na temperatura mais baixa $\left(130^{\circ} \mathrm{C}\right)$ apresentaram aspecto bastante irregular, enquanto que na temperatura de $170^{\circ} \mathrm{C}$, tanto o GER como o aspecto do produto foram satisfatórios.

Com base nesses ensaios preliminares, adotou-se umidade inicial de $25 \%$ e temperatura de $170^{\circ} \mathrm{C}$ para a extrusão.

Quanto aos níveis de adição dos derivados de levedura e de caseína foram testados 5\% e 10\%. Como era de interesse adicionar o maior nivel possivel de ingredientes e, como o processo transcorreu a contento com 10\% de adição e extrusão a $170^{\circ} \mathrm{C}$, as formulações e condições finalmente adotadas estão representadas na Tabela 2.

TABELA 2. Formulação das farinhas mistas e condições de extrusão.

\begin{tabular}{lcccc}
\hline Ingredientes $(\mathrm{g} / \mathrm{kg})$ & $\mathrm{FA}$ & $\mathrm{FAC}$ & $\mathrm{FE}$ & $\mathrm{FEC}$ \\
& $(10: 25 / 170)$ & $(10 / 10: 25 / 170)$ & $(10: 25 / 170)$ & $(10 / 10: 25)$ \\
\hline Autolisado & 100 & 100 & - & - \\
Extrato & - & - & 100 & 100 \\
Caseína & - & 100 & - & 100 \\
Farinha de & 650 & 550 & 650 & 550 \\
milho & & & & \\
Água & 250 & 250 & 250 & 250 \\
\hline
\end{tabular}

Símbolos usados: F, farinha de milho; A, autolisado de levedura; E, extrato de levedura; C, caseina.

Número entre parênteses: derivados de levedura ou caseína $10 \%$; umidade final da mistura $25 \%$; temperatura de extrusão $170^{\circ} \mathrm{C}$. 
A composição centesimal aproximada das farinhas extrusadas é apresentada na Tabela 3.

TABELA 3. Composição centesimal aproximada da farinha de milho e das farinhas mistas extrusadas

\begin{tabular}{lccccc}
\hline $\begin{array}{c}\text { Componente } \\
(\%)\end{array}$ & $\begin{array}{c}\mathrm{F} \\
(25,170)\end{array}$ & $\begin{array}{c}\mathrm{FE} \\
(10,25,170)\end{array}$ & $\begin{array}{c}\text { FEC } \\
(10 / 10 / 25,170)\end{array}$ & $\begin{array}{c}\text { FA } \\
(10,25,170)\end{array}$ & $\begin{array}{c}\text { FAC } \\
(10 / 10,25,170)\end{array}$ \\
\hline Proteína & 10,1 & 13,9 & 23,7 & 13,5 & 22,4 \\
$(\mathrm{~N} \times 6,25)$ & & & & & \\
Lipídios totais & 3,1 & 2,0 & 3,2 & 2,2 & 3,0 \\
Fibra total & 3,8 & 2,5 & 3,5 & 5,8 & 8,8 \\
Cinzas & 1,0 & 2,2 & 3,5 & 1,5 & 2,8 \\
Carboidrato & 82,0 & 79,4 & 66,1 & 77,0 & 63,1 \\
(diferença) & & & & & \\
\hline
\end{tabular}

Símbolos: F: farinha de milho; E: extrato de levedura; C: caseína; A: autolisado de levedura. Números entre parênteses representam: 10, concentração de derivado de levedura ou caseína; 25, umidade inicial da amostra; 170, temperatura de extrusão.

Os dados da Tabela 3 indicam um aumento de 35 a $40 \%$ na proteína, pela adição à farinha de milho de $10 \%$ de autolisado ou extrato de levedura. Quando se adicionou $10 \%$ cada de derivado de levedura e caseína, o teor de proteína aumentou cerca de $130 \%$. O teor de cinza aumentou com a adição de extrato, principalmente pelo teor mais elevado de $\mathrm{NaCl}$ usado durante a autólise. Os teores mais elevados de fibra são das formulações que receberam autolisado integral como ingrediente (FA e FAC). O teor mais elevado de carboidrato foi o da farinha de milho pura e o mais baixo da formulação com $10 \%$ de extrato de levedura mais 10\% de caseína (FEC).

Na Figura 1, é possível comparar o grau de expansão radial (GER), para a farinha de milho pura extrusada (F) e para as farinhas mistas contendo $10 \%$ de extrato ou de autolisado de levedura ou combinações de extrato/ caseína e autolisado/caseína na proporção de $10 \%$ (p/p) cada.

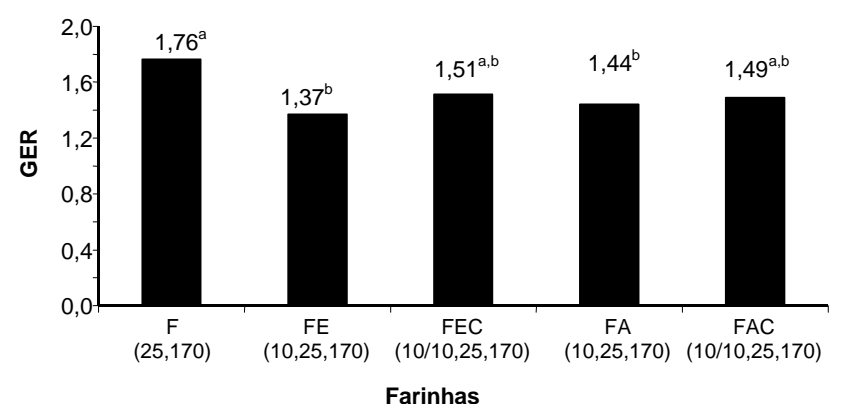

a, b Letras diferentes indicam resultados estatisticamente diferentes $(\mathrm{p}<0,05)$.

FIGURA 1. Graus de expansão radial da farinha de milho extrusada (F) e das farinhas mistas (FA, FE) adicionadas de autolisado ou extrato de levedura $(10 \% \mathrm{p} / \mathrm{p})$ ou adicionadas de derivados de levedura e de caseína C (10/10\% p/p). Umidade inicial da mistura $25 \%$, temperatura de extrusão $170{ }^{\circ} \mathrm{C}$.

A farinha de milho pura apresentou o maior GER $(1,76)$ e a farinha de milho com $10 \%$ de extrato apresentou o menor GER $(1,37), p<0,05$. As demais misturas apresentaram GER intermediários.
O elevado teor de amido da farinha de milho pura proporcionou um maior grau de expansão na extrusão. A adição de $10 \%$ de extrato diminuiu o GER, não somente em relação a $\mathrm{F}$, mas também em relação às demais misturas. A adição de $10 \%$ de caseína não afetou o GER, tanto na presença de extrato como de autolisado.

Os índices de absorção/retenção de água (IAA) e de solubilidade em água (ISA) para a farinha de milho crua e extrusada e para as farinhas mistas extrusadas, são mostrados na Figura 2. Nota-se que o IAA aumentou cerca de 2,5 vezes e o ISA quase 4 vezes, em função da extrusão. Ao compararmos a farinha de milho extrusada com as farinhas mistas, também extrusadas, conclui-se que o IAA variou pouco entre as farinhas extrusadas, tendo sido um pouco inferior para a mistura de farinha de milho e $10 \%$ cada de extrato de levedura e caseína. Quanto ao ISA, os valores mais elevados são para a farinha de milho com $10 \%$ de extrato de levedura (FE), seguida da farinha com $10 \%$ cada de extrato e caseína (FEC). As outras duas misturas (FA e FAC) não diferiram da farinha de milho extrusada ( $p>0,05)$. Os maiores valores de ISA nas farinhas contendo extrato de levedura ( $\mathrm{p}<$ $0,05)$, justificam-se pelo fato de o extrato ser formado apenas de sólidos solúveis.

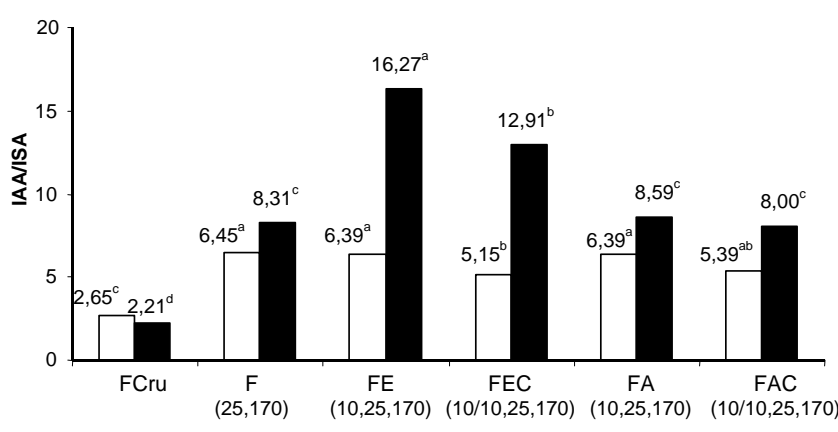

\footnotetext{
IIAA IISA

Farinhas

a. b. c, d Letras diferentes indicam resultados estatisticamente diferentes $(p<0,05)$.
}

FIGURA 2. Índices de absorção (retenção) de água (IAA) e de solubilidade em água (ISA) de farinha de milho crua e extrusada (Fcrua, F) e farinhas mistas extrusadas (FE, FEC, $\mathrm{FA}, \mathrm{FAC}$ ), processadas a $170^{\circ} \mathrm{C}$ e $25 \%$ de umidade inicial. $\mathrm{F}$, farinha de milho; E, extrato de levedura; A, autolisado de levedura; C, caseína.

O IAA depende da disponibilidade de grupos hidrofílicos e da capacidade de formação de gel das macromoléculas [7]. Esse índice está relacionado à capacidade de absorção e retenção de água pelos constituintes da matéria-prima. Durante a extrusão, os grãos de amido sofrem gelatinização e as proteínas são desnaturadas. Os grãos de amido gelatinizado absorvem mais água que no estado natural e as proteínas, devido a mudanças conformacionais e estruturais, têm seu balanço hidrofílico/hidrofóbico alterado, podendo contribuir para o aumento ou diminuição do IAA [7]. Pode-se notar que as formulações contendo autolisado (A) apresentam IAA que se aproximam mais de F, uma vez que o hidrolisado contém fibras solúveis que, pela ação do 
calor, tende a se gelatinizar, a exemplo do que acontece com o amido.

O ISA depende da quantidade de moléculas solúveis e também da intensidade e do tipo de reações que ocorrem durante a extrusão. Além da gelatinização do amido, que resulta na liberação da amilose e amilopectina de seus grânulos, poderá ocorrer também a dextrinização dos componentes do amido e outras reações que conduzem à formação de compostos de baixo peso molecular, que irão influir no ISA $[8,21]$.

A Figura 3 ilustra os efeitos da extrusão das diversas farinhas na viscosidade, em função do tempo (min) e da temperatura $\left({ }^{\circ} \mathrm{C}\right)$. Observando-se o que acontece com a farinha de milho pura, nota-se que a forma das curvas de viscosidade é completamente diferente para a farinha crua e extrusada. Na farinha de milho crua, a viscosidade é muito baixa no princípio, sobe muito rapidamente ao se elevar a temperatura de 50 para $95^{\circ} \mathrm{C}$ (entre 3 e $5 \mathrm{~min})$, permanece ao mesmo patamar ( 1.300cp) à temperatura de $95^{\circ} \mathrm{C}$, elevando-se novamente com o resfriamento até $50^{\circ} \mathrm{C}$, atingindo viscosidade máxima de $3.300 c p$. Já, a farinha de milho extrusada apresenta viscosidade maior que a crua a $50^{\circ} \mathrm{C}$, que se eleva lentamente com a temperatura, até $95^{\circ} \mathrm{C}$ ( $\left.500 \mathrm{cp}\right)$, mantendo esse valor depois de resfriada a $50^{\circ} \mathrm{C}$. Portanto, a farinha de milho crua apresentou viscosidade máxima cerca de 7,5 vezes maior que a farinha de milho extrusada.

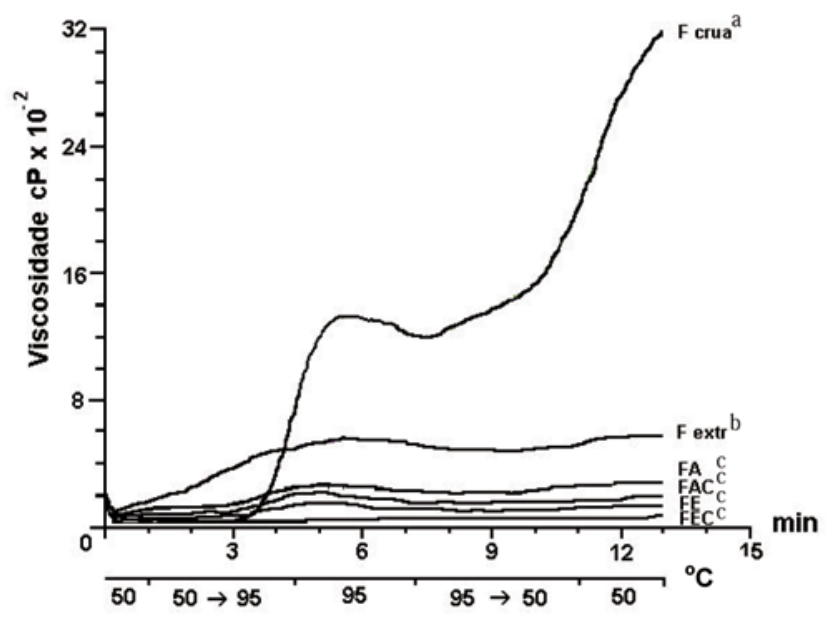

a. b.c Letras diferentes indicam resultados estatisticamente diferentes $(\mathrm{p}<0,05)$

FIGURA 3. Curvas de viscosidade, em função do tempo e da temperatura para farinhas de milho crua e extrusada ( $F$ crua e $\mathrm{F}$ extr) e para farinhas mistas extrusadas: farinha de milho com $10 \%$ de autolisado $\left(\mathrm{FA}_{10,25,170}\right)$; farinha de milho com $10 \%$ cada de autolisado e caseína $\left(\mathrm{FAC}_{10 / 10,25,170}\right)$; farinha de milho com $10 \%$ de extrato de levedura ( $\mathrm{FE}_{10,25,170}$ ); farinha de milho com $10 \%$ cada de extrato e caseína $\left(\mathrm{FEC}_{10 / 10,25,170}\right)$.

As demais farinhas (farinhas mistas extrusadas) apresentaram valores de viscosidade bastante baixos (valores máximos próximos de 220cp e mínimos ao redor de 120cp).
A Figura 4 (A, B) ilustra, com maior fidelidade, as curvas de viscosidade, em função do tempo e da temperatura, para as farinhas mistas (FA e FAC), cruas e extrusadas. A Figura 5 (A, B) ilustra os efeitos da extrusão sobre a viscosidade das farinhas FE e FEC. Observa-se que a extrusão exerceu um efeito marcante não somente na diminuição da viscosidade como na forma das curvas. A farinha $\mathrm{FE}$ (farinha de milho mais $10 \%$ de extrato de levedura) foi a que menos respondeu à elevação da temperatura de 50 a $95^{\circ} \mathrm{C}$ (Figura 5A). Uma característica marcante de todas as farinhas extrusadas é a de não apresentar aumento de viscosidade com o abaixamento da temperatura de $95^{\circ} \mathrm{C}$ para $50^{\circ} \mathrm{C}$, contrariamente ao que se observa nas mesmas farinhas mistas enquanto cruas. Esse fenômeno talvez possa ser explicado pela retrogradação do amido na extrusão e pela incapacidade das proteínas, já desnaturadas pela extrusão, formarem géis, mediante aquecimento e resfriamento.
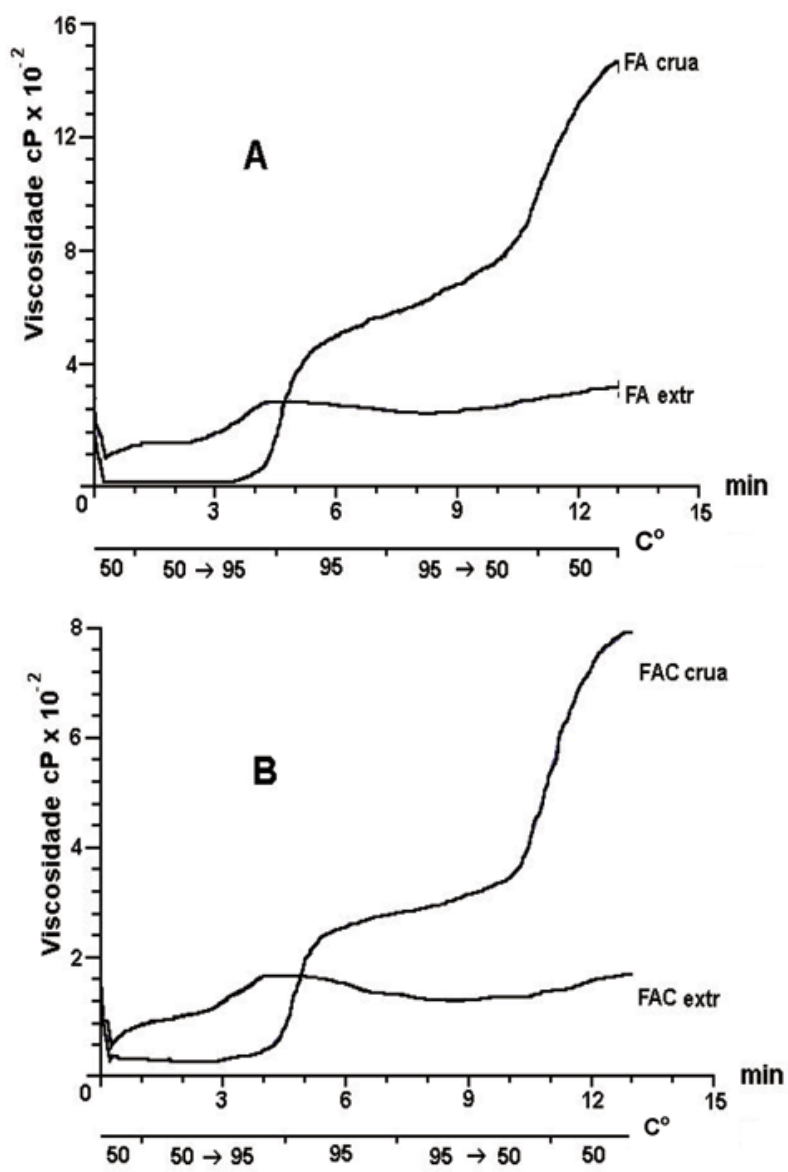

FIGURA 4. Curvas de viscosidade das farinhas mistas cruas e extrusadas em função do tempo e da temperatura: farinha de milho com 10\% de autolisado (FA crua e FA extr); farinha de milho com $10 \%$ cada de autolisado e caseína (FAC crua e FAC extr). 

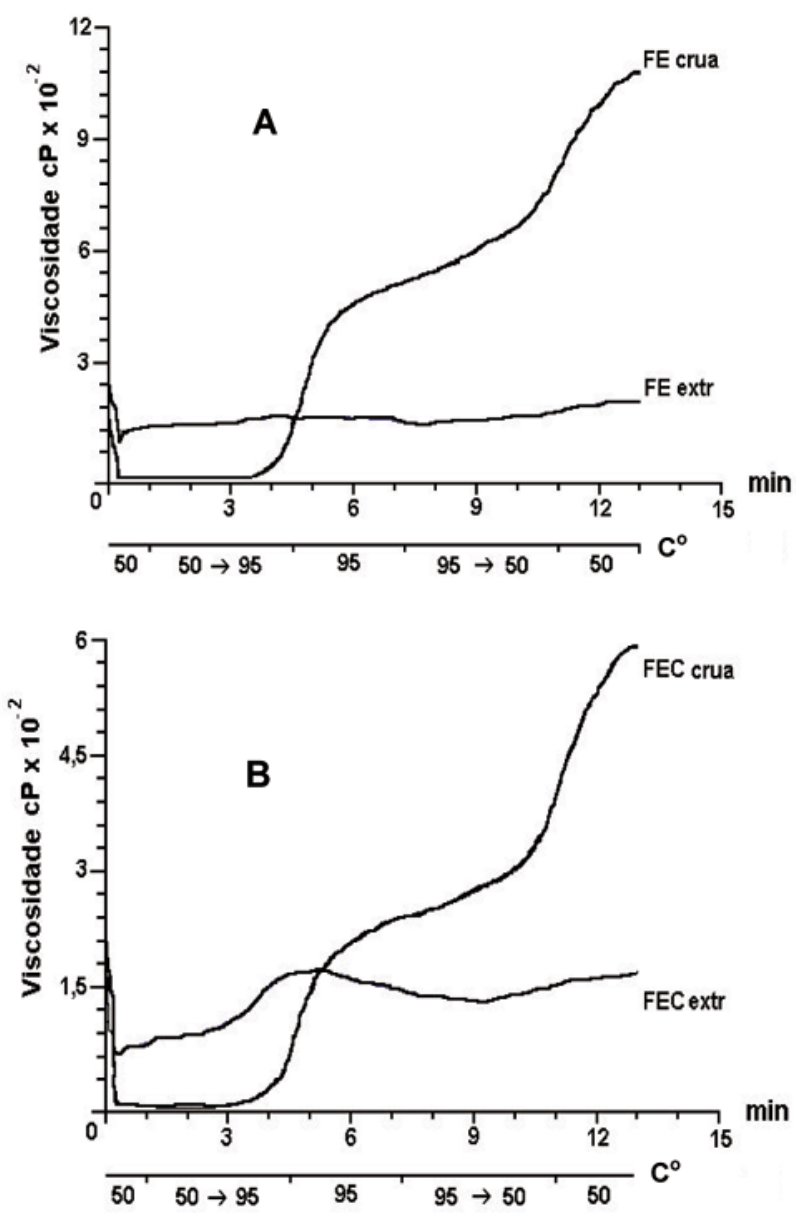

FIGURA 5. Curvas de viscosidade das farinhas mistas cruas e extrusadas em função do tempo e da temperatura: farinha de milho com $10 \%$ de extrato de levedura ( $\mathrm{FE}$ crua e $\mathrm{FE}$ extr); farinha de milho com $10 \%$ cada de extrato e caseína (FEC crua e FEC extr).

Em termos numéricos, os efeitos da extrusão e da presença, na formulação, de diferentes ingredientes na viscosidade final $\left(50^{\circ} \mathrm{C}\right)$, das farinhas estudadas são ilustrados na Tabela 4.

TABELA 4. Viscosidade final $\left(50^{\circ} \mathrm{C}\right)$ das farinhas de milho crua e extrusada (Fcrua, F) e de farinhas mistas extrusadas (FE, FEC, FA, FAC).

\begin{tabular}{lc}
\hline Tratamento & $\begin{array}{c}\text { Viscosidade final }(50 \stackrel{\circ}{\circ}) \\
\left(\mathrm{Cp} \times 10^{-2}\right)\end{array}$ \\
\hline F crua & $3.324,5^{\mathrm{a}}$ \\
F $(25,170)$ & $438,0^{\mathrm{b}}$ \\
FE $(10,25,170)$ & $195,5^{\mathrm{c}}$ \\
FEC $(10 / 10,25,170)$ & $187,7^{\mathrm{c}}$ \\
FA $(10,25,170)$ & $119,8^{\mathrm{c}}$ \\
FAC $(10 / 10,25,170)$ & $220,0^{\mathrm{c}}$ \\
\hline
\end{tabular}

F, farinha de milho; FE, farinha de milho com $10 \%$ de extrato de levedura; FEC farinha de milho com $10 \%$ cada de extrato de levedura e caseina; FA, farinha de milho com $10 \%$ de autolisado de levedura; FAC, farinha de milho com $10 \%$ cada de autolisado e caseína. ${ }^{\text {a, b. c }}$ Letras diferentes indicam resultados estatisticamente diferentes $(\mathrm{p}<0,05)$

\section{4 - CONCLUSÕES}

Os resultados do presente estudo permitem concluir: 1) a adição de $10 \%$ de autolisado de levedura à farinha de milho elevou o teor de proteína em 35\%, o teor de fibra em 53\% e diminuiu o teor de carboidrato em $6,5 \%$; 2) $10 \%$ de extrato de levedura elevou a concentração de proteína em $38 \%$ e o de cinzas em $120 \%$, ao mesmo tempo em que reduziu os teores de lipídios de 35,5\%, fibras totais de $34,2 \%$ e de carboidrato de 9,8\%; 3) a adição de $10 \%$ de caseína mais $10 \%$ de extrato de levedura elevou a concentração de proteínas em $135 \%$, o de minerais em $235 \%$ (1,0 para 3,5\%), ao mesmo tempo em que houve uma diminuição dos carboidratos de $24 \%$; 4) a adição à farinha de milho de $10 \%$ de autolisado de levedura mais $10 \%$ de caseína elevou a proteína em $122 \%$, o teor de fibra em $132 \%$, o de mineral em 180\% com uma diminuição de carboidrato de 30\%; 5) a adição de derivado de levedura isoladamente ou em combinação com caseína diminuiu o GER, em relação à farinha de milho pura, sendo que a maior diminuição observada foi com a adição de 10\% de extrato de levedura; 6) os índices de absorção de água (IAA) e de solubilidade em água (ISA) aumentaram significativamente na farinha de milho com a extrusão; 7) nas farinhas extrusadas o IAA não variou significativamente $(\mathrm{p}>0,05)$, enquanto que o ISA foi significativamente maior para as farinhas contendo extrato de levedura; 8) a extrusão diminuiu de maneira significativa $(\mathrm{p}<0,05)$ a viscosidade das farinhas em função do tempo e da temperatura, tanto para a farinha de milho pura como para as farinhas mistas; 9) a viscosidade das farinhas extrusadas variou menos que a das farinhas cruas em função da elevação, seguida de abaixamento da temperatura.

\section{5 - REFERÊNCIAS BIBLIOGRÁFICAS}

[1] A.O.A.C. - Association of Official Analytical Chemists, Official Methods of Analysis, 16 ${ }^{\text {th }}$ edition, vol. 1-2, Arlington, 1998.

[2] BLIGH, E.G.; DYER, W.J. A rapid method of total lipid extraction and purification. Canadian Journal of Biochemistry and Physiology, Ottawa, vol. 46, n. 1, p. 31-37, 1959.

[3] BORGES, P. F.Z.; SGARBIERI, V. C.; DIAS, N. F.G.P.; JACOBUCCI, H.B.; PACHECO, M.T.B.; BALDINI, V.L.S. Produção piloto de concentrados de proteínas de leite bovino: composição e valor nutritivo. Brazilian Journal of Food Technology, Campinas, vol. 5, p. 1-8, 2001.

[4] DZIEZAK, J.D. Yeasts and yeast derivatives: definition, characteristics, and processing. Food Technology, Chicago, vol. 41, n. 2, p. 103-121, 1987a.

[5] DZIEZAK, J.D. Yeasts and yeast derivatives: applications. Food Technology, Chicago, vol. 41, n. 2, p. 122-125, 1987b.

[6] GIESE, J. Proteins as ingredients: types, functions, applications. Food Technology, Chicago, vol. 49, n. 10, p. 50-60, 1994.

[7] GOMEZ, M.H.; AGUILERA, J.M. Changes in the starch fraction during extrusion cooking of corn. Journal of Food Science, Chicago, vol. 48, n. 2, p. 378-381, 1983.

[8] GUTKOSKI, L.C. Caracterização tecnológica de frações de 
moagem de aveia e efeito de umidade e temperatura de extrusão na sua estabilidade. Tese de doutorado, Universidade Estadual de Campinas, Campinas, 1997, 241p.

[9] HALÁSZ, A.; LÁSZTITY, R. Use of yeast biomass in food production. CRC Press, Boca Raton, 1991, 312p.

[10] KOLLAR, R.; STURDIK, E.; FARKAS, V. Induction and acceleration of yeast lysis by addition of fresh yeast autolysate. Biotechnology Letters, Northwood, vol. 13, n. 8, p. 543-546, 1991.

[11] McCORMICK, R. Unconventional protein sources diversity development choices. Prepared Foods, Chicago, vol. 156, n. 12, p. 135-136, 1987.

[12] MILLER, R.C. Low moisture extrusion: effects of cooking moisture on product characteristics. Journal of Food Science, Chicago, vol. 50, p. 249-253, 1985.

[13] PROSCKY, L.; ASP, N. G.; FURD, I.; DEVRIES, J.W.; SCWEIZER, T.F.; HARLAND, B.F. Determination of total dietary fiber in food products and total diets: interlaboratorial study. Journal of the Association of Official Analytical Chemists, vol. 67, n. 6, p. 10441052, 1984.

[14] RHEE, K.S.; CHO, S.H.; PRADAHN, A.M. Expanded extrudates from corn starch-lamb blends: process optimization using response surface methodology. Meat Science, Oxford, vol. 52, n. n, p. 127-134, 1999.

[15] SCHÖNHAUS, I.; SGARBIERI, V. C. Inherited characteristics of protein nutritive value of a new cultivar of maize (Nutrimaiz) in two stages of maturity. Journal of Agricultural and Food Chemistry, Washington, vol. 31, p. 1-7, 1983.
[16] SGARBIERI, V. C. A genética e a tecnologia a serviço da alimentação e da nutrição. Rev. Nutrição, Campinas, vol. 1, p. 45-55, 1988.

[17] SGARBIERI, V. C. Proteínas em alimentos protéicos: propriedades, degradações, modificações. Editora Varela, São Paulo, 1996, p. 259-335, 357p.

[18] SGARBIERI, V. C.; ALVIM, I.D.; VILELA, E.S.D.; BALDINI, V. L.S.; BRAGAGNOLO, n. Produção piloto de derivados de levedura (Saccharomyces sp.) para uso como ingrediente na formulação de alimentos. Brazilian Journal of Food Technology, Campinas, vol. 2, n. 12, p. 119-125, 1999.

[19] SINGH, N.; SEKHON, K.S.; NAGI, H.P.S. Effect of temperature on the extrusion behavior of flour from sound and sprouted wheat. Journal of Food Science and Technology, Mysore, vol. 31, n. 3, p. 233-235, 1994.

[20] SOUTHWARD, C.R. Use of casein and caseinates. In: Developments in dairy chemistry-4. Fox, p. F. (Ed.); Elsevier Applied Science Publishers, New York, 1989, $38 \mathrm{p}$.

[21] WHALEN, P. J.; BASON, M.L.; BOOTH, R.I.; WALKER, C.E.; WILLIAMS, P. J. Measurements of extrusion effects by viscosity profile using the rapid viscoanalyser. Cereal Foods World, Saint Paul, v. 42, n. 6, p. 469-475, 1977.

\section{6 - AGRADECIMENTOS}

Os autores agradecem o apoio financeiro da FAPESP e da COPERSUCAR para a realização desta pesquisa. 